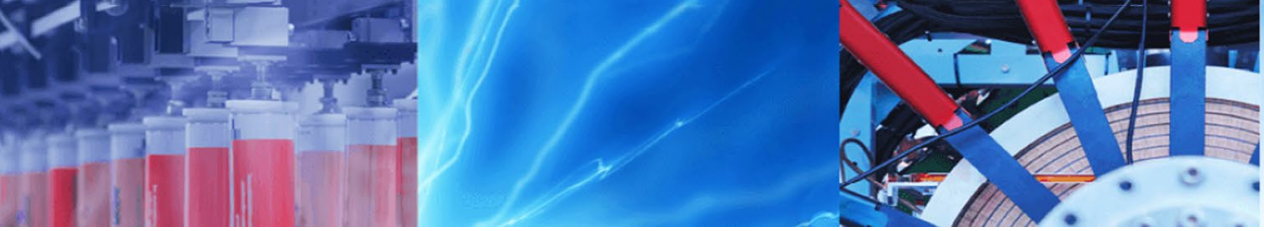

Research Article

\title{
A thermal method for obtention of 2 to 3 reduced graphene oxide layers from graphene oxide
}

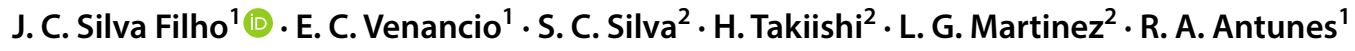

Received: 16 March 2020 / Accepted: 21 July 2020 / Published online: 29 July 2020

(c) Springer Nature Switzerland AG 2020

\begin{abstract}
In this work, a thermal reduction method was developed to obtain reduced graphene oxide ( $\mathrm{rGO}$ ) with 2 or 3 layers from graphene oxide (GO). The GO X-ray diffraction (XRD) patterns presented diffraction peak at $2 \theta=10^{\circ}$, which is related to (002) reflection. After heat treatment under nitrogen $\left(\mathrm{N}_{2}(\mathrm{~g})\right.$ ) atmosphere, this peak was shifted to $2 \theta=25^{\circ}$, presenting an interlayer distance of $3.8 \AA$, associated to $\mathrm{GO}$ reduction. $\mathrm{BET}$ analysis of modified $\mathrm{GO}$ samples identified an average pore diameter of $45.38 \AA$ and surface area of $23.06 \mathrm{~m}^{2} / \mathrm{g}$. In the case of $\mathrm{rGO}_{1}, \mathrm{rGO}_{2}$ and $\mathrm{rGO}_{3}$ samples, they presented surface areas from 32.47 to $612.74 \mathrm{~m}^{2} / \mathrm{g}$ and an average pore diameter of $108.21-149.54 \mathrm{~m}^{2} / \mathrm{g}$. Thermogravimetric analysis (TGA) indicated a higher mass loss between 150 and $230^{\circ} \mathrm{C}$. Raman spectra showed ID/IG ratios of $\mathrm{rGO}$ samples were higher than $\mathrm{GO}\left(1.36-\mathrm{GO} ; 1.45-\mathrm{rGO}_{1}, 1.87-\mathrm{rGO}_{3}\right)$ due to reducing $\mathrm{GO}$ and increasing $\mathrm{sp}^{2}$ clusters. XPS analysis revealed that the main carbon species in the samples were $\mathrm{sp}^{2}$-type bonds ( 14.99 at $\%$ for the $\mathrm{GO}$ and 47.85 at $\%$ for $\mathrm{rGO}_{3}$ ). The FTIR spectra of $\mathrm{rGO}_{1}, \mathrm{rGO}_{2}$ and $\mathrm{rGO}_{3}$ samples presented peaks at $3454.22 \mathrm{~cm}^{-1}$ (hydroxyl) and $1077.43 \mathrm{~cm}^{-1}(\mathrm{C}-\mathrm{O}$ ).
\end{abstract}

Keywords Reduced graphene oxide · Graphene oxide · Thermal treatment · Few layers graphene

\section{Introduction}

Carbon has a large number of allotropes and its properties are related to the hybridization state of the carbon atoms [1]. The chemical exfoliation of graphite has been considered as a strategy capable of producing graphene oxide (GO) [2]. Initially, the oxidation of graphite is promoted by introducing functional groups, such as hydroxyl and epoxide groups, which decrease the interactions between the layers. As a consequence, the spacing between them increases. A greater space between the layers facilitates the exfoliation of graphite oxide in simple sheets [3]. The synthesis of graphene from the reduction of graphene oxide allows the control of properties, such as electrical and thermal conduction, surface area and dispersibility in different solvents [4]. One method that has been used in the thermal reduction of $\mathrm{GO}$ is carried out in the presence of different gases and temperature conditions [5]. Among all the methods developed so far, thermal reduction of $\mathrm{GO}$ may be one of the most promising routes to obtain reduced graphene oxide ( $\mathrm{rGO}$ ) and graphene in large quantities [6]. Heating of GO in inert gas is called thermal reduction because the main objective is to produce a solid obtained from the carbon atoms transformed into reduced and oxidized forms that are mainly by-products of the gaseous phase of carbon oxide, such as $\mathrm{CO}$ and $\mathrm{CO}_{2}$ [7]. Owing to hydrophilic properties, associated with the presence of functional groups containing oxygen on its surface, GO and rGO can be, potentially, highly reactive to changes occurring in the surface of functional groups, during the reduction process [3]. The physical properties of graphene can be very sensitive to the number of layers. Therefore, in general, the number of layers and the crystallite size are fundamental to the understanding of these

$\square$ J. C. Silva Filho, jorgecsilvaf@gmail.com | ${ }^{1}$ Federal University of ABC, Santo André, Brazil. ${ }^{2}$ Materials Science and Technology Centre, Nuclear and Energy Research Institute, São Paulo, Brazil. 
properties [8]. In this work, GO was synthesized using the modified Hummers' method. The heat treatment for GO reduction to $\mathrm{rGO}$ was performed under inert nitrogen gas $\left(\mathrm{N}_{2}(\mathrm{~g})\right)$ atmosphere and partial pressure of $10 \mathrm{kPa}$, varying the time, heating rate and temperature of the process. The aim was to produce reduced graphene oxide with less than four layers and to control its surface area.

\section{Experimental details}

\subsection{Preparation of GO}

Graphene oxide was synthesized from graphite powder (Nacional de Grafite, at $99.99 \%$ purity) by using the modified Hummers' method. Graphite was added into a flask containing sulfuric acid $\left(\mathrm{H}_{2} \mathrm{SO}_{4}\right)$, potassium permanganate $\left(\mathrm{KMnO}_{4}\right)$ and phosphoric acid $\left(\mathrm{H}_{3} \mathrm{PO}_{3}\right)$. The mixture was kept under vigorous stirring, and then hydrogen peroxide $\left(\mathrm{H}_{2} \mathrm{O}_{2}\right)$ was added. Thereafter, the mixture was centrifuged, washed with hydrochloric acid $(\mathrm{HCl})$, subsequently washed and exfoliated by using methoxyethane.

\subsubsection{Preparation for $\mathrm{GO}$ heat treatment}

The heat treatments for obtaining the reduced graphene oxide samples are shown in Fig. 1. Three different routes were employed. The samples were designated as $\mathrm{rGO}_{1}$, $\mathrm{rGO}_{2}$ and $\mathrm{rGO}_{3}$, as indicated in Fig. 1. The samples were obtained using different temperature steps, times and heating rates. The choice of these processing routes was based on previous trials in our laboratory, aiming at increasing the mass of $\mathrm{rGO}$ obtained at the end of the

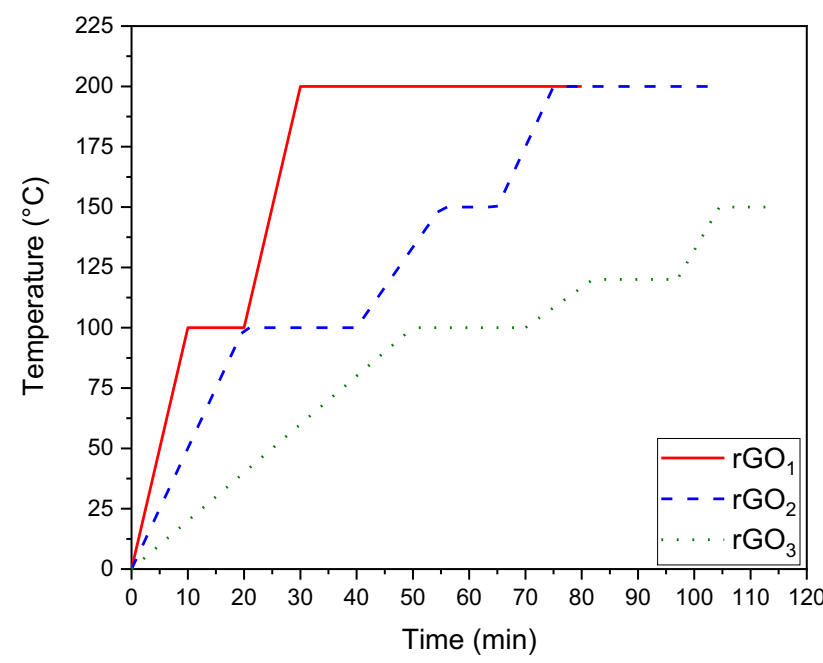

Fig. 1 Heat treatment procedures for obtaining the rGO samples thermal reduction process, eliminating micro-explosions and avoiding expansion of the $\mathrm{rGO}$ surface area.

\subsection{Characterization of GO and rGO}

Thermogravimetric analyses (TGA) were carried out by using TA Universal V4.5A instrument. Samples $(3 \mathrm{mg})$ were subject to heating at $20^{\circ} \mathrm{C} / \mathrm{min}$, from room temperature up to $800^{\circ} \mathrm{C}$ under nitrogen gas atmosphere. Fourier transform infrared spectroscopy (FTIR) spectra were recorded by a Nexus 870 spectrometer (Thermo Nicolet). X-ray photoelectron spectroscopy (XPS) was employed to analyze the surface chemical states of the different samples. The spectra were obtained by using a ThermoFisher Scientific $\mathrm{K}$-alpha + spectrometer operating with Al-ka $(1486.6 \mathrm{eV})$ radiation source. The pressure in the analysis chamber was approximately $10^{-7} \mathrm{~Pa}$. The spot size was $400 \mu \mathrm{m}$. The spectra were fitted using a combination of LorentzianGaussian curves in the CASA software. The Shirley algorithm was employed for background subtraction. Raman spectra were recorded in the range of $500-2000 \mathrm{~cm}^{-1}$ using a Raman WITEC instrument (Confman Raman Alpha 300r-green laser microscope, $532 \mathrm{~nm} ; 45 \mathrm{~mW}$ ). X-ray diffraction (XRD) experiments were carried out by using a Bruker D8 Advantage instrument with a copper tube, at $40 \mathrm{kV}$ and $30 \mathrm{~mA}$. XRD showed the interplanar spacing of the samples that can be determined by Bragg's Law and the crystallite size of was obtained by using Scherrer's equation. Brunauer, Emmelt and Teller (BET) surface and pore analyses were carried out by using adsorption analyzer equipment, model ASAP 2010 (Micromeritics).

\section{Results and Discussion}

TGA measurements were performed to assess the thermal stability of GO and $\mathrm{rGO}$ samples. Figure 2a shows the TGA curve for $\mathrm{GO}$. It indicates that its mass loss takes place in two stages. About $12 \%$ mass loss occurred below $120^{\circ} \mathrm{C}$ primarily due to the loss of water molecules adsorbed in GO [9]. In the second stage, roughly $2.55 \%$ of mass loss takes place at $\sim 280^{\circ} \mathrm{C}$ due to thermal decomposition of oxygen-containing functional groups of carboxyl, hydroxyl and epoxy groups in the edge and basal planes. Similar results were reported in the literature $[10,11]$. The mass loss becomes faster as temperature is raised. The residual mass at the end of the experiment was approximately $50 \%$.

Figure $2 \mathrm{~b}-\mathrm{d}$ are related to samples $\mathrm{rGO}_{1}, \mathrm{rGO}_{2}$ and $\mathrm{rGO}_{3}$. Comparing the TGA curve of GO in Fig. 2a with rGOs in Fig. $2 b-d$, it is evident that $\mathrm{GO}$ decomposes in different stages. The mass losses of $5 \%\left(\mathrm{rGO}_{1}, \mathrm{rGO}_{2}\right)$ and $8 \%\left(\mathrm{rGO}_{3}\right)$ at $120^{\circ} \mathrm{C}$ were attributed to decomposition of residual 

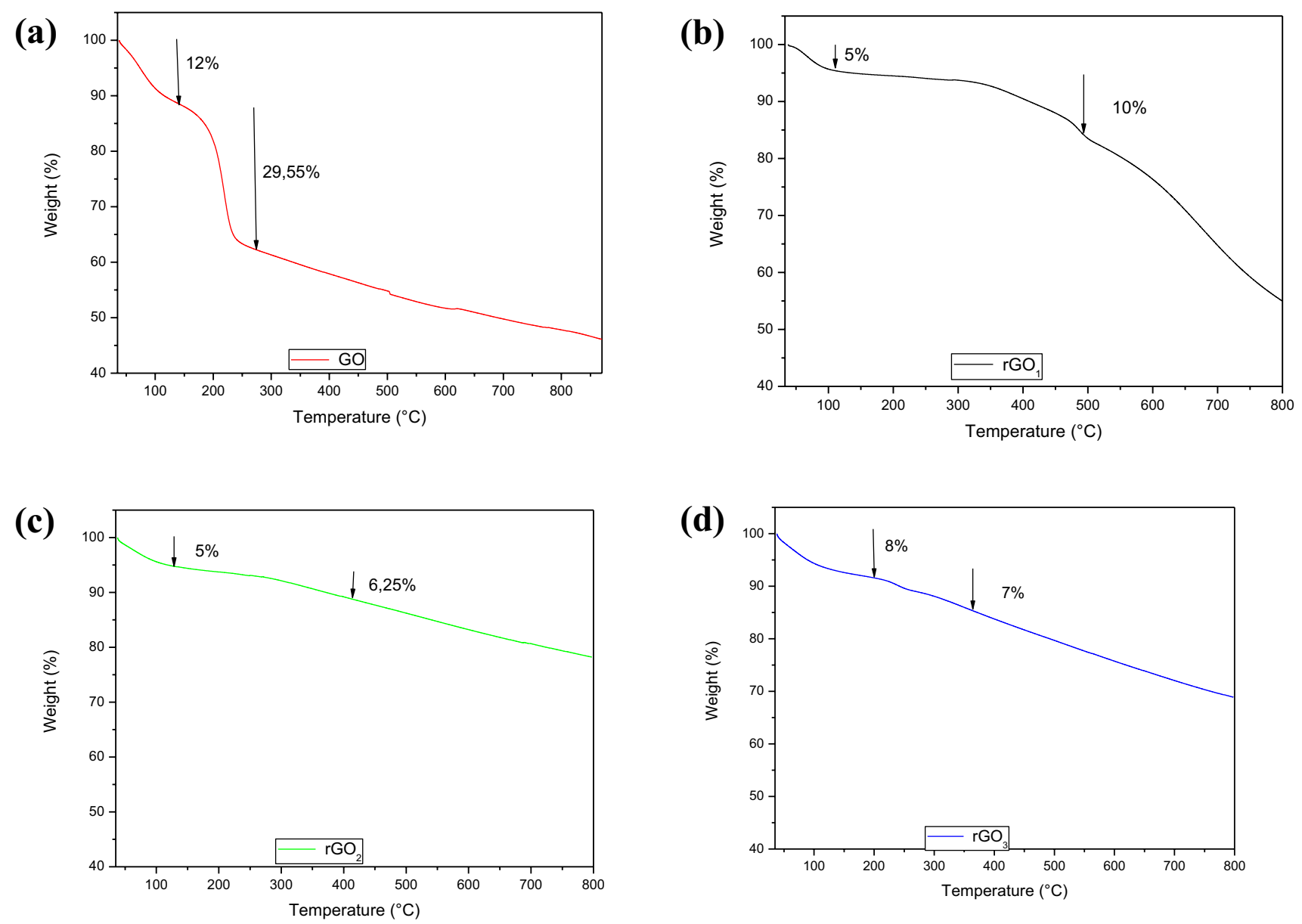

Fig. 2 TGA curves for a $\mathrm{GO}$ and for different $\mathrm{rGO}$ samples, $\mathbf{b} \mathrm{rGO}_{1}, \mathbf{c} \mathrm{rGO}_{2}$, and $\mathbf{d} \mathrm{rGO}_{3}$

water and volatiles [12]. Figure $2 \mathrm{~b}\left(\mathrm{rGO}_{1}\right)$ corresponds to the heat treatment carried out at a higher temperature and longer time, when compared with the other samples $\left(\mathrm{rGO}_{2}\right.$ and $\left.\mathrm{rGO}_{3}\right)$. Throughout the TGA analysis the mass gradually decreased in the case of $\mathrm{rGO}_{2}$ and $\mathrm{rGO}_{3}$, and decreased markedly for $\mathrm{rGO}_{1}$, showing a higher mass loss rate. This can be explained by the micro-explosions resulting from the highly exothermic reaction that occur at the end of the heat treatment for $\mathrm{rGO}_{1}$, due to the treatment conditions and residual impurities of GO synthesis [13].

In Fig. 3, BET results show the changes in the relative pressure and absorbed quantity of $\mathrm{N}_{2}$ for the different samples. From these analyses, $\mathrm{GO}$ presented an average pore diameter of $45.38 \AA$ and surface area of $23.06 \mathrm{~m}^{2} / \mathrm{g}$. Controlling the variables of the thermal reduction achieved surface area of $32.47 \mathrm{~m}^{2} / \mathrm{g}$ in $\mathrm{rGO}_{1}$ and $\mathrm{rGO}_{3}$ samples with an average pore diameter of $108.21 \AA$. While sample $\mathrm{rGO}_{2}$-that presented surface area expansion-has surface area $612.74 \mathrm{~m}^{2} / \mathrm{g}$ and average pore diameter $149.54 \AA$.

Distinction between the explosive and non-explosive character of the thermal reduction process depends on

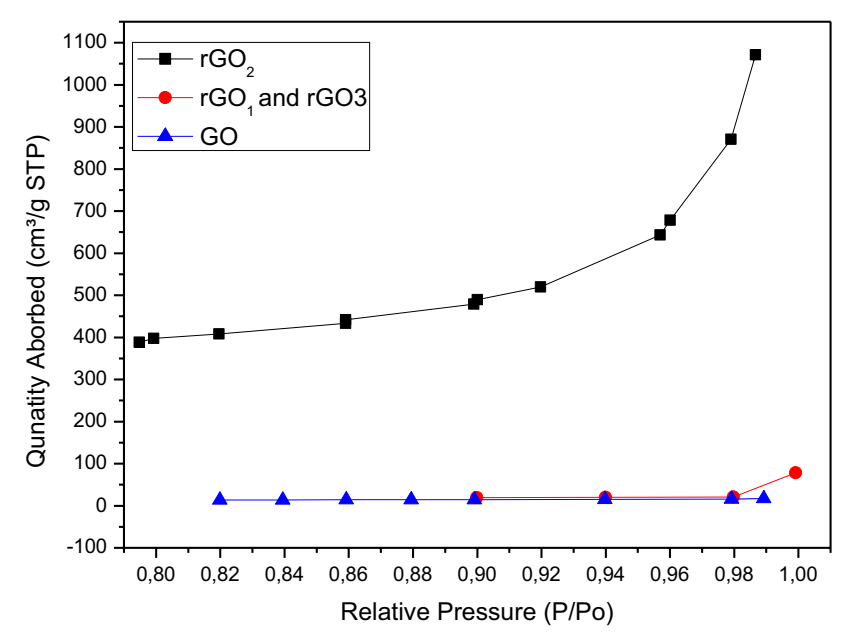

Fig. 3 BET curves for a GO and rGOs

its experimental parameters. Therefore, the temperature, heating rate and step employed in the thermal processing of $\mathrm{rGO}_{1}$, resulted in an explosive process which could be 
avoided when decreasing heating rate and temperatures were employed such as in the production of $\mathrm{rGO}_{2}$ and $\mathrm{rGO}_{3}$. However, when the heating rate is still high $\left(\mathrm{rGO}_{2}\right.$ sample), it results in surface area expansion. In the $\mathrm{rGO}_{3}$ sample, the heating rate and reduction of the treatment time enabled process control and avoided the occurrence of explosion $\left(\mathrm{rGO}_{1}\right)$ and surface area expansion $\left(\mathrm{rGO}_{2}\right)$. Explosive reduction leads to higher surface areas, as fracture causes early gas release that limits internal pressure development [13]. These different surface areas and average pore diameters are closely related to the structure and number of layers of the graphene oxide species, as also observed in the literature [14].

Figure 4 presents the FTIR spectra of GO and rGOs. The peak at $3452.22 \mathrm{~cm}^{-1}$ is related to $\mathrm{OH}$ [15]. Peaks at $2362.76 \mathrm{~cm}^{-1}$ may be assigned to the axial atmospheric $\mathrm{CO}_{2}$ vibrations [16]. Other peaks were found at $1715.51 \mathrm{~cm}^{-1}$ which can be assigned to carbonyl groups ((C=O from carboxylic acids or ketones) [15]; $1619.62 \mathrm{~cm}^{-1}$

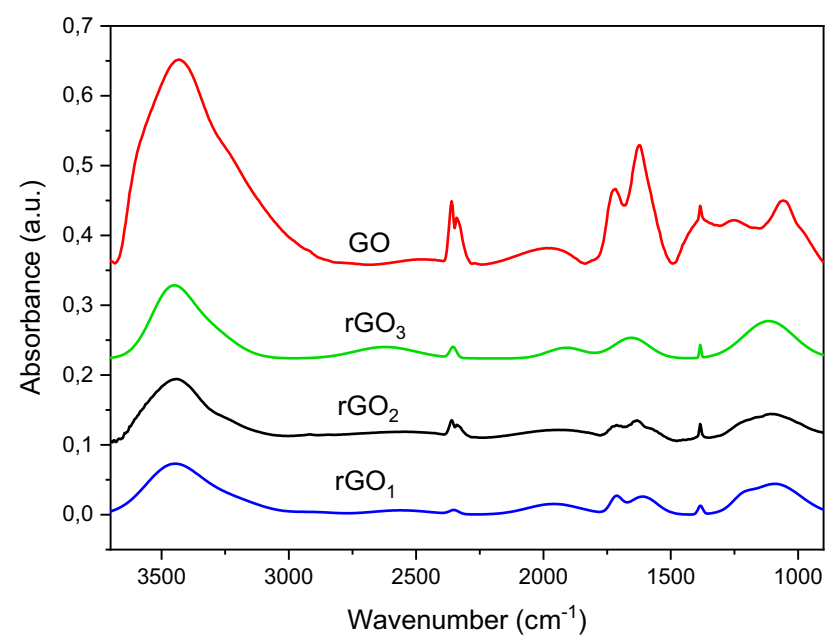

Fig. 4 FTIR spectra of GO and rGOs
$(\mathrm{C}=\mathrm{C})$, which normally has low intensity because it is related to conjugated alkenes [17]; $1381.33 \mathrm{~cm}^{-1}\left(\mathrm{CH}_{3}\right)$, angular deformation; $1077.43 \mathrm{~cm}^{-1}$ (C-O), alcohol [12].

Characteristic XPS spectra for the GO and rGO samples in the $\mathrm{C} 1 \mathrm{~s}$ and $\mathrm{O} 1 \mathrm{~s}$ regions are presented in Figs. 5 and 6 , respectively. The main chemical species and their atomic concentrations are summarized in Tables 1 and 2 . Figure 5 shows four peaks in the $\mathrm{C} 1 \mathrm{~s}$ region: carbon $\mathrm{sp}^{2}$, at $284.70 \mathrm{eV}(14.99 \mathrm{at} \%), \mathrm{C}-\mathrm{OH}$, at $286.60 \mathrm{eV}(48.07 \mathrm{at} \%)$, $\mathrm{C}-\mathrm{O}-\mathrm{C}$, at $287.88 \mathrm{eV}(26.88 \mathrm{at} \%)$ and $\pi-\pi^{*}$, at $290.70 \mathrm{eV}$ (10.06 at\%) [18-20]. The O $1 \mathrm{~s}$ region of the GO sample presented three different components at $532.18 \mathrm{eV}$ (18.35 at\%), $534.60 \mathrm{eV}$ (76.62 at\%), $535.70 \mathrm{eV}$ (5.03 at\%), which are related to $\mathrm{C}=\mathrm{O}, \mathrm{C}-\mathrm{O}-\mathrm{C}$ and $\mathrm{H}_{2} \mathrm{O}$ groups $[5,21]$, respectively.

Figure 6 shows the XPS spectra in the C1s (a) and (b) $\mathrm{O} 1 \mathrm{~s}$ regions of $\mathrm{rGO}_{1}, \mathrm{rGO}_{2}$ and $\mathrm{rGO}_{3}$. When the heat treatment was performed at $2{ }^{\circ} \mathrm{C} / \mathrm{min}$ with three temperature steps (route for obtaining $\mathrm{rGO}_{3}$ ) the $\mathrm{C} 1 \mathrm{~s}$ region presented only two different components whereas three types of carbon bonds were found in the $\mathrm{C} 1 \mathrm{~s}$ region of the pristine graphene oxide (GO). Also, an increase in atomic percentage of the $\mathrm{sp}^{2}$ carbon bonds was observed for the three rGO samples. Table 1 shows the heat treatment was effective at increasing the quantity of carbon-carbon double bonds. Initially, GO sample had 14.99 at\% and, after heat treatment, $\mathrm{rGO}_{1}, \mathrm{rGO}_{2}$ and $\mathrm{rGO}_{3}$ samples had 35.51 at $\%, 33.14$ at $\%$ and 47.85 at $\% \mathrm{sp}^{2}$. Another factor was the reduction of hydroxyl groups (Table 2-O1s regions) in the rGOs, $\mathrm{rGO}_{2}$ (23.91 at\%) e $\mathrm{rGO}_{3}(12.90$ at\%), when compared to $\mathrm{GO}\left(48.07\right.$ at\%). For the $\mathrm{rGO}_{1}$ e $\mathrm{rGO}_{3}$ samples, it was not possible to eliminate adsorbed $\mathrm{H}_{2} \mathrm{O}$ from the surface, showing that a high heating rate does not promote water removal during the heat treatment.

Figure 7 shows the Raman spectra obtained for $\mathrm{GO}$ and $\mathrm{rGO}$ samples. The positions of $\mathrm{D}, \mathrm{G}$ and $2 \mathrm{D}$ bands are indicated in the figure as well as the ID/IG ratios. Two
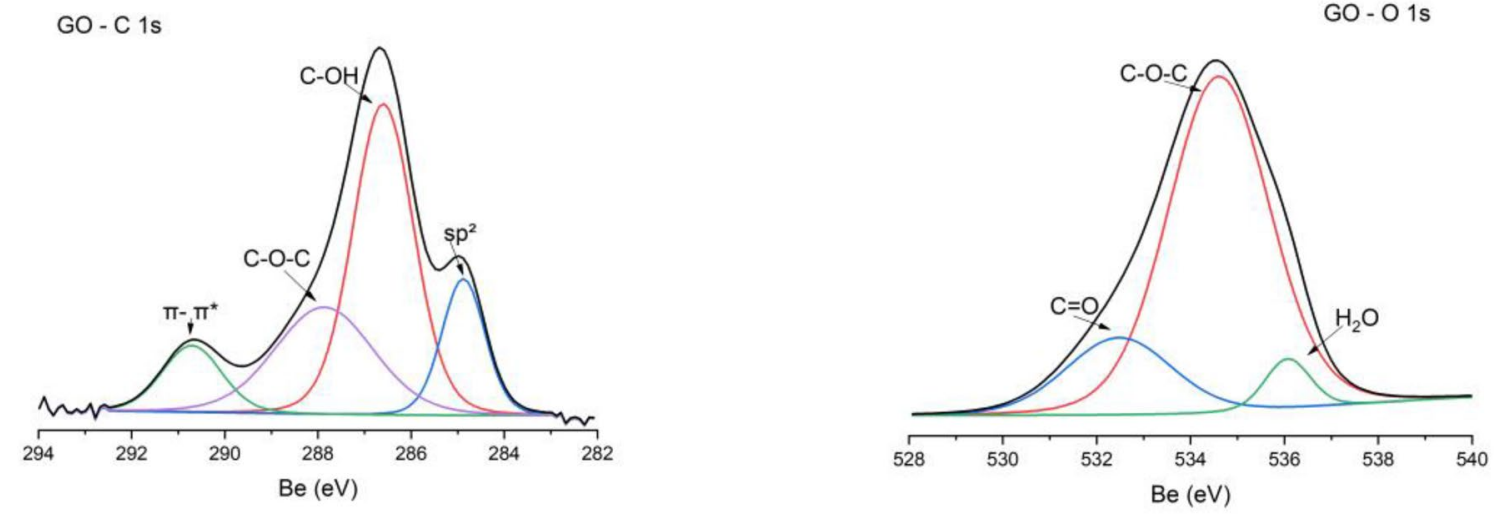

Fig. 5 XPS spectra in the C1s $\mathbf{a}$ and $\mathbf{b} 01 \mathrm{~s}$ regions of GO 
(a)

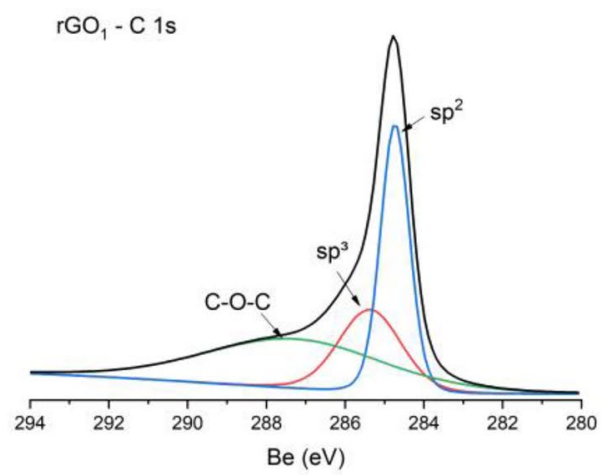

(c) $\mathrm{rGO}_{2}-\mathrm{C} 1 \mathrm{~s}$

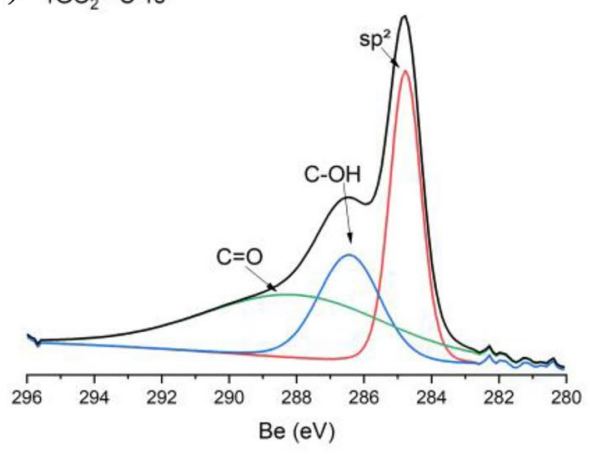

(e) $\mathrm{rGO}_{3}-\mathrm{C} 1 \mathrm{~s}$

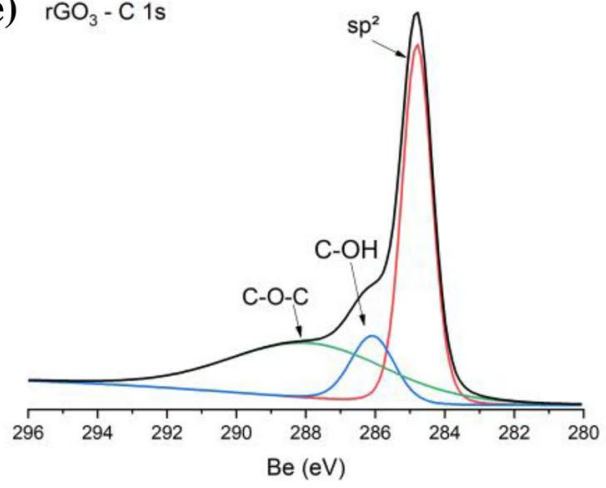

(b)

$\mathrm{rGO}_{1}-\mathrm{O} 1 \mathrm{~s}$

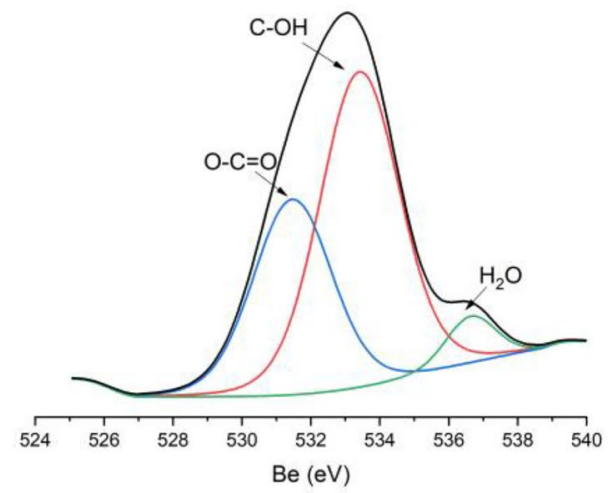

(d)

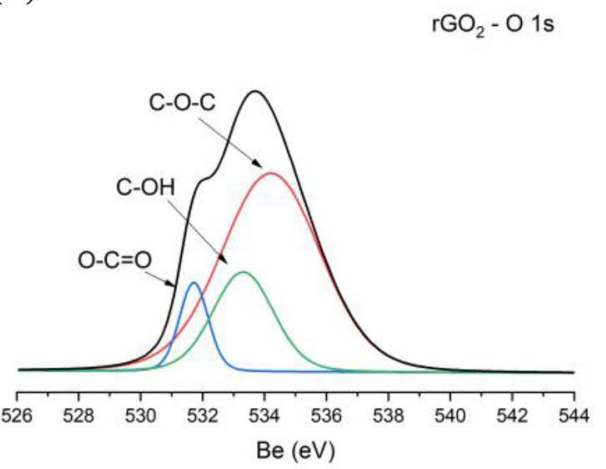

(f)

$\mathrm{rGO}_{3} . \mathrm{O} 1 \mathrm{~s}$

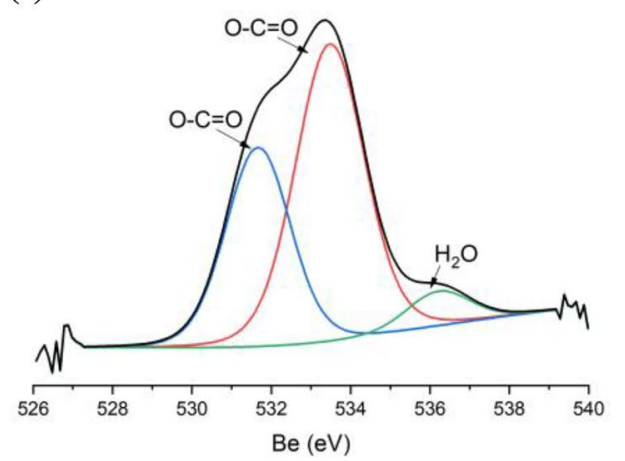

Fig. 6 XPS spectra in the $\mathrm{C} 1 \mathrm{~s}(\mathbf{a}, \mathbf{c}, \mathbf{e})$ and $(\mathbf{b}, \mathbf{d}, \mathbf{f}) \mathrm{O} 1 \mathrm{~s}$ regions of $\mathrm{rGO}_{1}, \mathrm{rGO}_{2}$ and $\mathrm{rGO}_{3}$

Table 1 Fitting results for the $\mathrm{C} 1 \mathrm{~s}$ region of $\mathrm{GO}$ and $\mathrm{rGO}$

\begin{tabular}{lllllll}
\hline Sample & \multicolumn{6}{l}{ Component (at.\%) } \\
\cline { 2 - 6 } & $\mathrm{C} \mathrm{sp}^{2}$ & $\mathrm{C} \mathrm{sp}^{3}$ & $\mathrm{C}-\mathrm{OH}$ & $\mathrm{C}-\mathrm{O}-\mathrm{C}$ & $\mathrm{C}=\mathrm{O}$ & $\pi-\pi^{*}$ \\
\hline $\mathrm{GO}$ & 14.99 & - & 48.07 & 26.88 & - & 10.06 \\
$\mathrm{rGO}_{1}$ & 35.51 & 33.68 & - & 40.81 & - & - \\
$\mathrm{rGO}_{2}$ & 33.14 & - & 23.91 & - & 42.95 & - \\
$\mathrm{rGO}_{3}$ & 47.85 & - & 12.90 & 39.25 & - & - \\
\hline
\end{tabular}


Table 2 Fitting results for the $\mathrm{O} 1 \mathrm{~s}$ region of $\mathrm{GO}$ and $\mathrm{rGO}$

\begin{tabular}{llllll}
\hline Sample & \multicolumn{5}{l}{ Component (at.\%) } \\
\cline { 2 - 6 } & $\mathrm{O}-\mathrm{C}=\mathrm{O}$ & $\mathrm{C}=\mathrm{O}$ & $\mathrm{C}-\mathrm{OH}$ & $\mathrm{C}-\mathrm{O}-\mathrm{C}$ & $\mathrm{H}_{2} \mathrm{O}$ \\
\hline $\mathrm{GO}$ & - & 18.35 & - & 76.62 & 5.03 \\
$\mathrm{rGO}_{1}$ & 35.93 & - & 58.56 & - & 5.50 \\
$\mathrm{rGO}_{2}$ & 9.07 & - & 21.41 & 69.52 & - \\
$\mathrm{rGO}_{3}$ & 36.112 & - & 57.72 & - & 6.15 \\
\hline
\end{tabular}

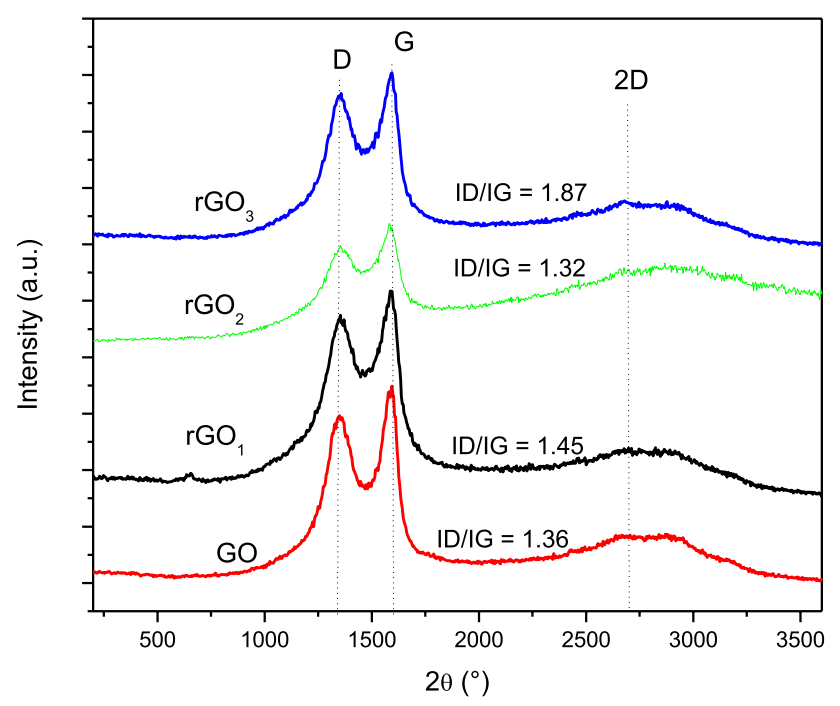

Fig. 7 Raman spectra of GO and rGOs

bands are seen, one at $1579.42 \mathrm{~cm}^{-1}$ related to $\mathrm{sp}^{2}$ carbon atoms ( $G$ band) and the second one at $1364.57 \mathrm{~cm}^{-1}$ ( $D$ band) which is attributed to defects related to $\mathrm{sp}^{3}$ carbons, located in the $\mathrm{sp}^{2}$ carbon crystal lattice. A verybroad band at $2685.62 \mathrm{~cm}^{-1}$ is also observed, the $2 \mathrm{D}$ band, which is related to graphene structure defects $[22,23]$. After the heat treatments, $D, G$ and 2D bands are shifted in $\mathrm{rGO}_{1}\left(1360.06 \mathrm{~cm}^{-1}, 1576.85 \mathrm{~cm}^{-1}\right.$, $\left.2716.39 \mathrm{~cm}^{-1}\right), \mathrm{rGO}_{2}\left(1359.21 \mathrm{~cm}^{-1}, 1580.81 \mathrm{~cm}^{-1}\right.$, $\left.2673.23 \mathrm{~cm}^{-1}\right)$ and $\mathrm{rGO}_{3}\left(1347.59 \mathrm{~cm}^{-1}, 1593.05 \mathrm{~cm}^{-1}\right.$, $2725.13 \mathrm{~cm}^{-1}$ ) samples. The higher intensity of $D$ bands with respect concerning $G$ bands indicates an increase in the amount of disordered phase in rGOs. The present oxygen atoms cause increase in the interplanar distance and change the materials structures vibrations. The ID/IG ratio is a measure of the disorder degree and is inversely proportional to the average cluster size $\mathrm{sp}^{2}$ [24]. Figure 7 shows the ID/IG ratios of $\mathrm{rGO}$ were higher than that of $\mathrm{GO}$ (1.36), revealing an increasing trend for rGO1 (1.45) and rGO3 (1.87). This suggests that new or more graphitic domains are formed and the $\mathrm{sp}^{2}$ cluster number is increased $[25,26]$. This information was also observed from the XPS fitting results shown in Table 1 as

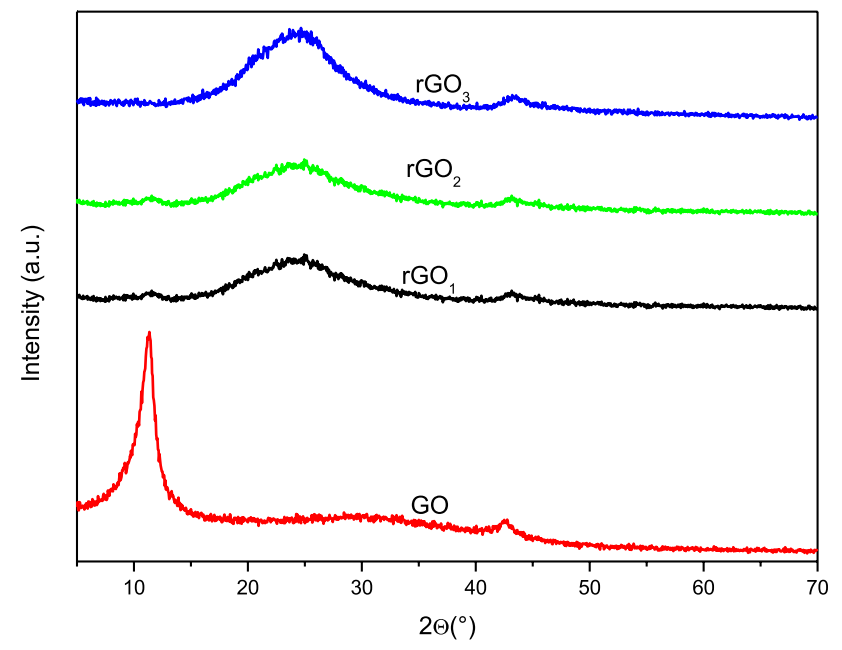

Fig. 8 XRD patterns of GO and rGOs

Table 3 Crystal size and interatomic distance of GO and rGOs

\begin{tabular}{llll}
\hline Samples & $d$ middle $(\AA)$ & $\begin{array}{l}\text { Crystallite size } \\
(\mathrm{nm})\end{array}$ & $\begin{array}{l}\text { Crystal- } \\
\text { line } \\
\text { layers }\end{array}$ \\
\hline $\mathrm{GO}$ & 7.9 & 56.7 & 7.2 \\
$\mathrm{rGO}_{1}$ & 3.7 & 10.7 & 2.9 \\
$\mathrm{rGO}_{2}$ & 3.7 & 10.8 & 2.9 \\
$\mathrm{rGO}_{3}$ & 3.8 & 9.2 & 2.4 \\
\hline
\end{tabular}

the content of $\mathrm{sp}^{2}$ bonds increased from $14.99 \%$ for $\mathrm{GO}$ to $47.88 \%$ for $\mathrm{rGO}_{3}$.

Figure 8 shows XRD patterns for $\mathrm{GO}$ and $\mathrm{rGOs}$. Using Bragg's Law and Sherrer's equation ( $k=0,9 \AA$ ) the values of interplanar spacing, crystallite size and number of crystalline layers were obtained, as displayed in Table 3. The peak centered at $2 \theta \approx 12^{\circ}$ corresponds to the (002) crystalline plane. After heat treatment and thermal reduction, the peak was shifted to $2 \theta \approx 24^{\circ}$. Since this peak corresponds to the layer-to-layer distance $(d)$ [27], shifting X-ray peaks of $r G O s$ to a higher angle results in decreasing $d$-spacing, showing that the thermal reduction process decreases the interplanar spacing. These results indicate a separation of the layers and oxygen removal during the thermal reduction process, i.e., TGA and XRD results demonstrated that the GO synthesis was successfully performed with the reduction of samples $\mathrm{rGO}_{1}, \mathrm{rGO}_{2}$ and $\mathrm{rGO}_{3}$. When these results are compared to the literature, it is possible to observe that different temperatures are used for the thermal reduction treatment, i.e., from 500 to $1000{ }^{\circ} \mathrm{C}$ [28-30], and heating rates between 10 and $80^{\circ} \mathrm{C} / \mathrm{s}$. These works show narrower interlayer spacing, i.e., $4 \AA$ [28, 31]. However, in our work the reduction of graphene oxide 
was carried out at a maximum temperature of $200^{\circ} \mathrm{C}$, which resulted in the change of the characteristic GO XRD reduction peak, reducing crystallite size and maintaining the number of layers between 2 and 3, regardless of the parameters used in the thermal reduction route.

In Table 3, the distances between the electronic layers, the crystallite size and number of crystalline layers are shown. For GO, the interplanar distance was $7.9 \AA$ and for the samples subjected to heat treatment $\left(\mathrm{rGO}_{1}, \mathrm{rGO}_{2}\right.$ and $\mathrm{rGO}_{3}$ ), these distances were between 3.7 and $3.8 \AA$. The decrease in crystallite size may also be observed from $56.7 \mathrm{~nm}$ for GO sample to $10.7 \mathrm{~nm}, 10.8 \mathrm{~nm}$ and $9.2 \mathrm{~nm}$ for $\mathrm{rGO}_{1}, \mathrm{rGO}_{2}$ and $\mathrm{rGO}_{3}$, respectively. The number of crystalline layers of $\mathrm{rGO}$ s was also decreased with respect to concerning GO. The results show that reduced graphene oxide produced by thermal exfoliation at high temperature exhibits a few-layered structure. Hence, it has higher specific surface area. Similar results were obtained by other authors for thermally reduced graphene oxide samples $[32,33]$.

\section{Conclusions}

The heat treatment method developed in this work was efficient at reducing $7 \mathrm{GO}$ layers to 2 to 3 rGO layers, as observed by XRD. The thermal reduction process made it possible to change the crystallite size, distance between layers, number of crystalline layers, surface area and chemical composition. It was shown for the first time that the rGO thermal reduction was carried out without explosion and with a decrease in the total number of $\mathrm{rGO}$ layers, from $8 \mathrm{GO}$ layers to $3 \mathrm{rGO}$ layers at the end of the thermal reduction process. Raman and XPS spectra confirm the increase in the number of carbon $\mathrm{sp}^{2}$ bonds at different thermal reduction routes. BET analysis confirms the possibility of controlling the expansion of rGOs depending on the process parameters such as heating rate, temperature step and treatment time.

Acknowledgements INCT Project: CNPQ (465719/2014-7), FAPESP (2014/50887-4) and CAPES (23038000776/2017-54), the Materials Science and Technology Center (CCTM/IPEN), Nuclear Fuel Center (CCN/IPEN), Laboratory of Electrical Engineering (POLI/USP), the Multiuser Laboratory of Functional Polymers (UFABC), the National Graphite and IPEN-CNEN/SP for the infrastructure.

Funding This study was funded by INCT Project: CNPQ (465719/20147), FAPESP (2014/50887-4) and CAPES (23038000776/2017-54).

\section{Compliance with ethical standards}

Conflict of interest The authors declare that they have no conflict of interest.

\section{References}

1. Yan P, Zhang B, Su W, Qi DW (2019) Surface chemistry of nanocarbon: characterization strategies from the viewpoint of catalysis and energy conversion. Carbon 143:915-936. https://doi. org/10.1016/j.carbon.2018.11.085

2. Stankovich S, Piner RD, Nguyen ST, Ruoff RS (2006) Synthesis and exfoliation of isocyanate-treated graphene oxide nanoplatelets. Carbon 44:3342-3347. https://doi.org/10.1016/j.carbo n.2006.06.004

3. Sengupta I, Chakraborty S, Talukdar M, Pal SK, Chakraborty S (2018) Thermal reduction of graphene oxide: how temperature influences purity. J Mater Res 33:4113-4122. https://doi. org/10.1557/jmr.2018.338

4. Toh SY, Loh KS, Kamarudin SK, Daud WRW (2014) Graphene production via electrochemical reduction of graphene oxide: synthesis and characterisation. Chem Eng J 251:422-434. https ://doi.org/10.1016/j.cej.2014.04.004

5. Drewniak S, Muzyka R, Stolarczyk A, Pustelny T, KotyczkaMorańska M, Setkiewicz M (2016) Studies of reduced graphene oxide and graphite oxide in the aspect of their possible application in gas sensors. Sensors 16:103. https://doi.org/10.3390/ s16010103

6. Chen Y, Egan GC, Wan J, Zhu S, Jacob RJ, Zhou W, Fu K (2016) Ultra-fast self-assembly and stabilization of reactive nanoparticles in reduced graphene oxide films. Nat Commun 7:12332. https://doi.org/10.1038/ncomms12332

7. Gao X, Jang J, Nagase S (2009) Hydrazine and thermal reduction of graphene oxide: reaction mechanisms, product structures, and reaction design. J Phys Chem C 114:832-842. https://doi. org/10.1021/jp909284g

8. Kauling AP, Seefeldt AT, PisoniDP PR, Bentini R, Oliveira RV, Castro Neto AH (2018) The Worldwide graphene flake production. Adv Mater 30:1803784. https://doi.org/10.1002/adma.20180 3784

9. Gao R, Hu N, Yang Z, Zhu Q, Chai J, Su Y, Zhang Y (2013) Like graphene-Ag composite films with enhanced mechanical and electrical properties. Nanoscale Res Lett 8:32. https://doi. org/10.1186/1556-276X-8-32

10. Rajagopalan B, Chung JS (2014) Reduced chemically modified graphene oxide for supercapacitor electrode. Nanoscale Res Lett 9:535. https://doi.org/10.1186/1556-276X-9-535

11. Ossonon BD, Bélanger D (2017) Synthesis and characterization of sulfophenyl-functionalized reduced graphene oxide sheets. RSC Adv 7:27224-27234. https://doi.org/10.1039/C6RA28311J

12. Silva Filho JC, Soares E, Venancio E, Silva S, Takiishi (2017) Influência do tratamento térmico na redução do óxido de grafeno. ISSN 2358-2359, Doi: 10.5151/phypro-viii-efa-18

13. Qiu Y, Guo F, Hurt R, Külaots I (2014) Explosive thermal reduction of graphene oxide-based materials: mechanism and safety implications. Carbon 72:215-223. https://doi.org/10.1016/j. carbon.2014.02.005

14. Dai JF, Wang GJ, Ma L, Wu CK (2015) Surface properties of graphene: relationship to graphene-polymer composites. Rev Adv Mater Sci 40:60-71

15. Si Y, Aamulski ETS (2008) Synthesis of water soluble graphene. Nano Lett 8:1679-1682. https://doi.org/10.1021/nl080604h

16. Priante F, Salim M, Ottaviano L, Perrozzi F (2018) XPS study of graphene oxide reduction induced by (100) and (111)-oriented Si substrates. Nanotechnology 29:075704

17. Yang B, Liu Z, Guo Z, Zhang W, Wan M, Qi X, Zhong H (2014) In situ green synthesis of silver-graphene oxide nanocomposites by using tryptophan as a reducing and stabilizing agent and their application in SERS. Appl Surf Sci 316:22-27. https://doi. org/10.1016/j.apsusc.2014.07.084 
18. Wi G (2015) The chemistry of graphene oxide. Graphene oxide. Springer 39:61-95. https://doi.org/10.1039/B917103G

19. Shim S, Kim KT, Lee J, Jo W (2012) Facile method to functionalize graphene oxide and its application to poly (ethylene terephthalate)/graphene composite. ACS Appl Mater Interfaces 4:4184-4191. https://doi.org/10.1021/am300906z

20. Jovanovic SP, Markovi ZM, Svrgiannis Z, Dramicanin MD, Arcudi F, Pv PV, Markovi BMT (2017) Enhancing photoluminescence of graphene quantum dots by thermal annealing of the graphite precursor. Mater Res Bull 93:183-193. https://doi.org/10.1016/j. materresbull.2017.04.052

21. Bagri A, Mattevi C, Acik M, Chabal YJ, Cchhowalla M, Shenoy VB (2010) Structural evolution during the reduction of chemically derived graphene oxide. Nat Chem 2:581. https://doi. org/10.1038/nchem.686

22. Ferrari AC, Meyer JC, Scardaci V, Casiraghi C, Lazzeri M, Mauri F, Geim AK (2006) Raman spectrum of graphene and graphene layers. Phys Rev Lett 97:187401. https://doi.org/10.1103/PhysR evLett.97.187401

23. Wu JB, Lin ML, Cong X, Liu HN, Tan PH (2018) Raman spectroscopy of graphene-based materials and its applications in related devices. Chem Soc Rev 47:1822-1873. https://doi.org/10.1039/ $\mathrm{C} 6 \mathrm{CS} 00915 \mathrm{H}$

24. Perez LA, Bajales N, Lacconi GI (2019) Raman spectroscopy coupled with AFM scan head: a versatile combination for tailoring graphene oxide/reduced graphene oxide hybrid materials. Appl Surf Sci. https://doi.org/10.1016/j.apsusc.2019.143539

25. Guoa Y, Suna X, Liua Y, Wangb W, Qiua H, Gao J (2012) One pot preparation of reduced graphene oxide (RGO) or Au (Ag) nanoparticle-RGO hybrids using chitosan as a reducing and stabilizing agent and their use in methanol electrooxidation. Carbon 50:2513-2523. https://doi.org/10.1016/j.carbon.2012.01.074

26. Wang S, Dong Y, He C, Gao Y, Jia N, Chen Z, Song W (2017) The role of $\mathrm{sp}_{2} / \mathrm{sp}_{3}$ hybrid carbon regulation in the nonlinear optical properties of graphene oxide materials. RSC Advances 78:53643-53652. https://doi.org/10.1039/C7RA10505C

27. Cullity BD (1956) Elements of X-ray diffraction. Add Ison-Wesley Publishing Company Inc, Oxford

28. Yang H, Kannappan S, Pandian AS, Jang JH, Lee YS, Lu W (2017) Rapidly annealed nanoporous graphene materials for electrochemical energy storage. J Mater Chem A 5:23720-23726. https ://doi.org/10.1039/C7TA07733E

29. De Silva KKH, Huang HH, Joshi R, Yoshimura M (2020) Restoration of the graphitic structure by defect repair during the thermal reduction of graphene oxide. Carbon 166:74-90. https:// doi.org/10.1016/j.carbon.2020.05.015

30. Ambrosi A, Chua CK, Bonanni A, Pumera M (2014) Electrochemistry of graphene and related materials. Chem Rev 114:71507188. https://doi.org/10.1021/cr500023c

31. Zhou Y, Lin X, Huang Y, Guo Y, Gao C, Xie G, Jiang Y (2016) Impact of further thermal reduction on few-layer reduced graphene oxide film and its $\mathrm{np}$ transition for gas sensing. Sens Actuators B Chem 235:241-250. https://doi.org/10.1016/j.snb.2016.05.078

32. Wypych $\mathrm{G}$ (2019) Graphene important results and applications. Mater Performance Character. https://doi.org/10.1016/B978-1927885-51-2.50005-5

33. Sekimoto Y, Ohtani R, Nakamura M, Koinuma M, Lindoy LF, Hayami S (2017) Tuneable pressure effects in graphene oxide layers. Sci Rep 7:12159. https://doi.org/10.1038/s41598-017-12444-x

Publisher's Note Springer Nature remains neutral with regard to jurisdictional claims in published maps and institutional affiliations. 